\title{
Prediction of Future Uniform Milk Prices in Florida Federal Milk Marketing Order 6 from Milk Futures Markets
}

\author{
A. De Vries ${ }^{1}$ and S. Feleke \\ Department of Animal Sciences, University of Florida, Gainesville 32611
}

\begin{abstract}
This study assessed the accuracy of 3 methods that predict the uniform milk price in Federal Milk Marketing Order 6 (Florida). Predictions were made for 1 to 12 mo into the future. Data were from January 2003 to May 2007. The CURRENT method assumed that future uniform milk prices were equal to the last announced uniform milk price. The F+BASIS and F+UTIL methods were based on the milk futures markets because the futures prices reflect the market's expectation of the class III and class IV cash prices that are announced monthly by USDA. The F+BASIS method added an exponentially weighted moving average of the difference between the class III cash price and the historical uniform milk price (also known as basis) to the class III futures price. The F+UTIL method used the class III and class IV futures prices, the most recently announced butter price, and historical utilizations to predict the skim milk prices, butterfat prices, and utilizations in all 4 classes. Predictions of future utilizations were made with a Holt-Winters smoothing method. Federal Milk Marketing Order 6 had high class I utilization $(85 \pm$ $4.8 \%)$. Mean and standard deviation of the class III and class IV cash prices were $\$ 13.39 \pm 2.40 /$ cwt (1 $\mathrm{cwt}=45.36 \mathrm{~kg})$ and $\$ 12.06 \pm 1.80 /$ cwt, respectively. The actual uniform price in Tampa, Florida, was $\$ 16.62$ $\pm 2.16 /$ cwt. The basis was $\$ 3.23 \pm 1.23 /$ cwt. The $\mathrm{F}+\mathrm{BASIS}$ and F+UTIL predictions were generally too low during the period considered because the class III cash prices were greater than the corresponding class III futures prices. For the 1- to 6-mo-ahead predictions, the root of the mean squared prediction errors from the F+BASIS method were $\$ 1.12, \$ 1.20, \$ 1.55, \$ 1.91$, $\$ 2.16$, and $\$ 2.34 / \mathrm{cwt}$, respectively. The root of the mean squared prediction errors ranged from $\$ 2.50$ to $\$ 2.73 /$ cwt for predictions up to 12 mo ahead. Results from the F+UTIL method were similar. The accuracies of the F+BASIS and F+UTIL methods for all 12 fore-
\end{abstract}

Received February 29, 2008.

Accepted July 20, 2008.

${ }^{1}$ Corresponding author: devries@ufl.edu

cast horizons were not significantly different. Application of the modified Mariano-Diebold tests showed that no method included all the information contained in the other methods. In conclusion, both F+BASIS and F+UTIL methods tended to more accurately predict the future uniform milk prices than the CURRENT method, but prediction errors could be substantial even a few months into the future. The majority of the prediction error was caused by the inefficiency of the futures markets to predict the class III cash prices.

Key words: futures market, prediction, forecast, milk price

\section{INTRODUCTION}

Accurate prediction of future milk prices is important for income risk management, for example, for timely management of possible cash flow shortfalls or when using the futures and options markets to manage the variation in milk price risk (St-Pierre and Jones, 2001). Milk prices also affect herd expansions and culling decisions. Evaluation of methods that predict future milk prices in Florida and elsewhere is lacking, however.

The predictability of milk prices depends on the milk pricing system. In many parts of the United States, the milk price is determined by federal milk marketing orders (FMMO). Florida is in FMMO 6, except for the far western part of the state, which is in FMMO 7. The regulations in the FMMO are complicated and detailed and have been periodically adjusted since their inception in 1933 (Swantz, 1962). The current 10 FMMO have their origins with the 1996 Farm Bill, which resulted in a fundamental overhaul of the US milk pricing system (Bailey and Tozer, 2001).

Milk is priced in an FMMO according to how it will be used. Class I milk is used for fluid milk products. Class II is used for soft products such as ice cream. Class III milk is used for cheese products, and class IV milk is used for butter products and NDM (Bailey and Tozer, 2001). Four of the 10 FMMO, including FMMO 6, use the skim milk/butterfat pricing system because milk in these areas is used mainly for fluid consumption (class I milk). Under this pricing system, producer prices are based on the uniform skim milk price and the uniform 
butterfat price. The uniform skim milk price is an average of class I, II, III, and IV skim milk prices weighted by use in the market. Similarly, the uniform butterfat price is a weighted average of the butterfat prices for each class. Skim milk and butterfat prices of each class are calculated from FMMO formulas and the prices for dry whey, NDM, butter, and cheese surveyed weekly by the National Agricultural Statistics Service (Appendix). Weights of the class prices are the utilizations of skim milk and butterfat in each class. The uniform milk price is a weighted average value of the uniform skim milk price and butterfat price in $3.5 \%$ butterfat content milk (USDA-AMS, 2007). The actual (mailbox) price dairy producers receive equals the uniform milk price plus producer-specific price adjustments, such as cooperative premiums, dues, and hauling charges (Maynard et al., 2005).

Futures contracts for class III and IV whole milk that are traded at the Chicago Mercantile Exchange may be used as a price discovery tool of future class III and IV milk prices and, through their relationship with skim milk prices, of future uniform milk prices. Futures contracts are traded every trading day and expire up to 24 mo in the future (CME, 2007). Contract prices settle at the corresponding class III and class IV cash prices announced monthly by USDA. The class III futures price reflects the market's expectation for the class III whole milk price for the month of production (Sanders and Manfredo, 2005). These authors concluded that the class III milk futures predictions were at least as good as quarterly predictions from time-series models and from USDA experts at the 1-quarter and 3-quarter forecast horizons.

Fortenbery et al. (1997) studied the expected price dynamics between fluid milk futures contracts and cash prices received for milk from 1988 to 1995. Based on their results, they expected a strong relationship between the futures market and the milk price in areas that are part of the FMMO system. The accuracy of price predictions in their study was not directly apparent. Jesse and Schuelke (2002) provided a systematic method for predicting class III and class IV prices based on trend projections and historical economic relationships between total US milk production, product prices, and inventory levels, but did not discuss the accuracy of their price predictions. Petrov (1999) used production quantities and inventory levels to predict milk prices. His Bayesian method appears to generate prediction errors of less than $5 \%$ of the milk prices $(\approx$ $\$ 0.60 / \mathrm{cwt} ; 1 \mathrm{cwt}=45.36 \mathrm{~kg}$ ) over a forecast horizon of up to 6 mo (St-Pierre and Jones, 2001).

Methods that predict future milk prices have not been frequently analyzed. There is evidence, however, that the milk futures markets provide useful information for milk price discovery. The objective of this study was to investigate the accuracy of 3 methods to predict the uniform milk price in Tampa, Florida, in FMMO 6 for up to 12 mo into the future. Two methods depend on the class III and class IV futures contract prices, and a simple method was added for comparison. The relative importance of the different sources of prediction errors was also investigated.

\section{MATERIALS AND METHODS}

\section{Data}

Data for this study included the daily traded class III and class IV futures prices for up to 12 mo in the future; cash prices for the 4 classes; advanced and announced prices for butter, NDM, cheese, and dry whey; utilizations of skim milk and butterfat; the class I price differential; and actual uniform prices in FMMO 6 for January 2003 to May 2007. The source was the University of Wisconsin dairy markets Web site at http://future.aae. wisc.edu (accessed Sept. 1, 2007). Daily futures prices were averaged by calendar month. Thus, observations were available for $53 \mathrm{mo}$. Predictions of future prices were calculated starting after January 2003, depending on the forecast period. For example, 6-mo-ahead predictions were calculated for August 2003 through May 2007. Not all class IV futures contracts were traded every month, with the number of unavailable contracts increasing almost linearly from $0 \%$ for the 1-mo-ahead contracts to $92 \%$ for the 12 -mo-ahead contracts. When a contract was unavailable, the futures price in the previous month was used. Advanced prices are announced by USDA on or before the 23rd of the month preceding the month of production. Actual prices are announced on or before the fifth of the month following the month of production.

\section{Prediction Methods}

Three methods were used to predict uniform milk prices up to 12 mo into the future. The simple CURRENT method assumed that future uniform prices would be the same as the most recently announced uniform price, regardless of the forecast horizon.

The F+BASIS (futures and basis) method used the exponentially weighted moving averages of the differences between historical uniform prices and class III cash prices (ewmabasis) since January 2003, and added those to the class III futures prices to predict future uniform prices in month $\mathrm{t}-\mathrm{i}$ for month $\mathrm{t}$, where $\mathrm{t}$ is the month for which the price is predicted and $\mathrm{i}$ is the number of months ahead. Bailey and Tozer (2001) refer to the difference between the historical uniform 
Table 1. Prediction formulas for the 4 classes of skim milk for the F+UTIL method

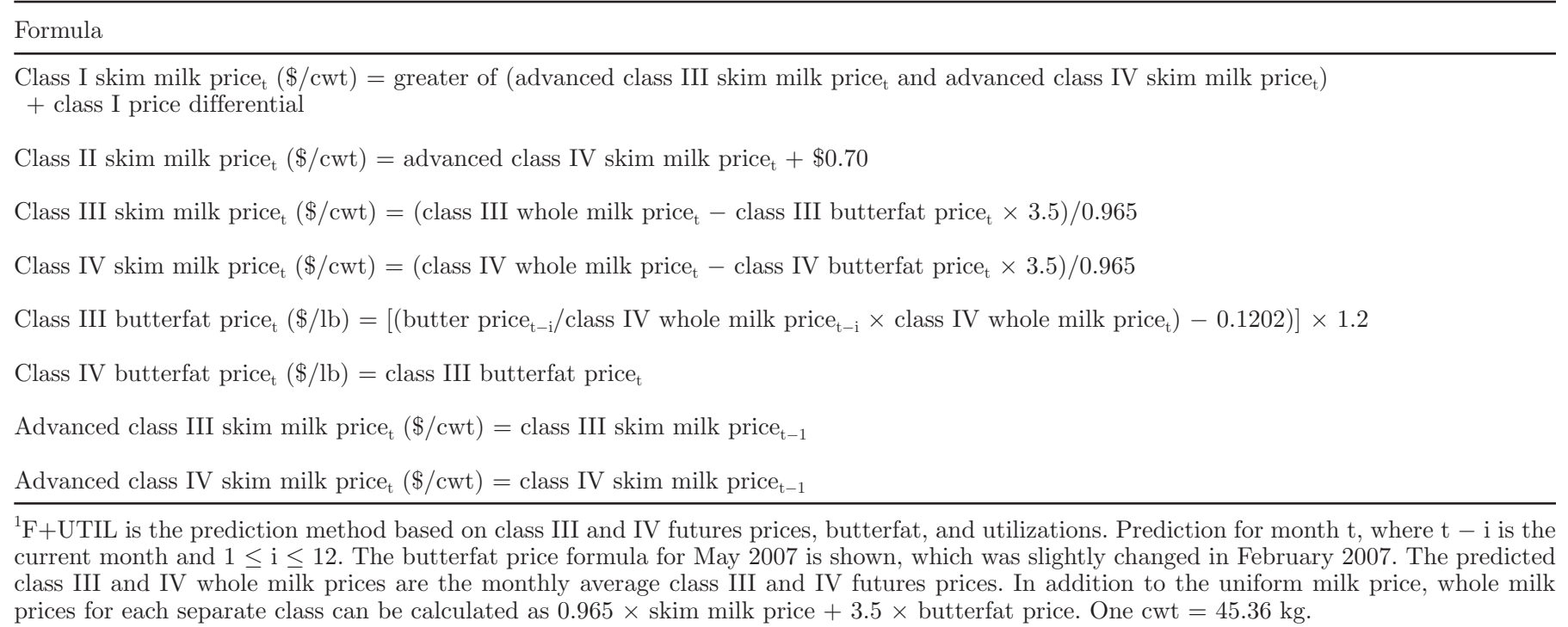

price and the class III cash price as "basis." Therefore, ewmabasis $_{\mathrm{t}-\mathrm{i}}=\lambda \times$ basis $_{\mathrm{t}-\mathrm{i}}+(1-\lambda) \times$ ewmabasis $_{\mathrm{t}-\mathrm{i}-1}$, where $\lambda$ is the smoothing parameter.

The F+UTIL (futures and utilization) method used the class III and class IV futures prices and the most recently announced butter price to predict the skim milk prices and butterfat prices in all 4 classes. The F+UTIL method was thought to be more complete and accurate than the CURRENT and F+BASIS methods. Future butter prices were predicted from the class IV futures price and the ratio of the most recently announced butter price and the class IV cash price (Table 1). The Holt-Winters smoothing method with multiplicative seasonality (Williams, 1987) was applied to historical utilizations to predict the utilizations of skim milk and butterfat in each of the 4 classes. The Holt-Winters method accounts for both the trend and seasonality in time series data. The method has proved effective, automatic, and simple to use to predict time series of data (Makridakis et al., 1982). Optimal smoothing constants were estimated for each of the 8 utilizations. The uniform milk price prediction for month $\mathrm{t}$ in month $\mathrm{t}-\mathrm{i}$ is then given by the products of the skim milk prices and skim milk utilizations and the products of the butterfat prices and butterfat utilizations summed across all classes.

All calculations were performed with Microsoft Excel 2003 (Microsoft, Redmond, WA). The parameters of the F+BASIS and the F+UTIL methods were estimated with the add-in Solver, which minimized the sum of the squared prediction errors of all available data. Comparisons with $P<0.05$ were declared significantly different from 0 .

\section{Evaluation of Prediction Accuracy}

A prediction must include an estimate of both expectation (mean) and dispersion (variance) if it is to be useful in risk management (St-Pierre and Jones, 2001). Prediction error $\left(e_{t}\right)$ was calculated as predicted $\left(p_{t}\right)$ minus actual price $\left(a_{t}\right), e_{t}=p_{t}-a_{t}$, for all months t. Bias, or the systematic deviation from expectation, was measured as the mean error (ME). Dispersion of the prediction error was measured by the standard deviation (SD). Because large positive and negative prediction errors offset each other, the mean absolute error (MAE) is also presented. The root of the mean squared error (RMSE) is the expected value of the prediction error. The RMSE is a combined estimate of both expectation and dispersion and is therefore a more comprehensive measure of prediction error than the ME and MAE. The RMSE is a traditional measure of accuracy of a prediction method (Diebold and Mariano, 1995; Sanders and Manfredo, 2005). These authors also point out problems with using only the RMSE to compare prediction methods.

Diebold and Mariano (1995) found Wilcoxon's signedrank test (WSR) to perform well among several tests to test whether 2 competing prediction methods had the same accuracy. The WSR assumes symmetry of the loss differential $\mathrm{w}_{\mathrm{t}}=\mathrm{g}\left(\mathrm{e}_{1 \mathrm{t}}\right)-\mathrm{g}\left(\mathrm{e}_{2 \mathrm{t}}\right)$, where $\mathrm{e}_{1 \mathrm{t}}$ and $\mathrm{e}_{2 \mathrm{t}}$ are prediction errors of methods 1 and 2 for month $t$ and $\mathrm{g}()$ is an arbitrary function mapping the prediction errors into an economic loss. In the current study, $g\left(e_{t}\right)$ $=\mathrm{e}_{\mathrm{t}}^{2}$ was used. The WSR tests the sum of the ranks of the absolute values of the positive $\mathrm{w}_{\mathrm{t}}$.

Harvey et al. (1997) modified the asymptotic test discussed by Diebold and Mariano (1995) and recom- 
Table 2. Descriptive statistics of monthly prices and utilizations in Federal Milk Marketing Order 6 (Tampa, FL) from January 2003 to May 2007

\begin{tabular}{|c|c|c|c|c|c|c|c|}
\hline Description & Type $^{2}$ & Mean & $\mathrm{SD}$ & Minimum & Median & Maximum & Corr $^{3}$ \\
\hline \multirow[t]{4}{*}{ Whole milk $(\$ / \text { cwt })^{1}$} & Class I & 13.28 & 2.38 & 9.64 & 13.62 & 21.13 & 0.99 \\
\hline & Class II & 12.62 & 1.51 & 10.43 & 12.90 & 16.62 & 0.78 \\
\hline & Class III & 13.39 & 2.40 & 9.11 & 13.60 & 20.58 & 0.86 \\
\hline & Class IV & 12.06 & 1.80 & 9.73 & 12.30 & 18.48 & 0.74 \\
\hline Butter $(\$ / \mathrm{lb})$ & Advanced & 1.40 & 0.29 & 1.05 & 1.30 & 2.16 & 0.82 \\
\hline Butter $(\$ / \mathrm{lb})$ & Announced & 1.41 & 0.30 & 1.05 & 1.34 & 2.20 & 0.73 \\
\hline Cheese $(\$ / \mathrm{lb})$ & Announced & 1.42 & 0.22 & 1.08 & 1.40 & 2.13 & 0.81 \\
\hline $\operatorname{NDM}(\$ / \mathrm{lb})$ & Announced & 0.91 & 0.16 & 0.80 & 0.86 & 1.67 & 0.32 \\
\hline Dry whey $(\$ / \mathrm{lb})$ & Announced & 0.29 & 0.14 & 0.14 & 0.26 & 0.78 & 0.31 \\
\hline Class I differential ( $\$ / \mathrm{cwt})$ & Class I & 4.00 & 0.00 & 4.00 & 4.00 & 4.00 & - \\
\hline \multirow[t]{6}{*}{ Skim milk $(\$ /$ cwt $)$} & Class I & 12.17 & 1.64 & 9.91 & 11.96 & 16.98 & 0.85 \\
\hline & Class II & 7.40 & 0.91 & 6.61 & 7.11 & 11.50 & 0.30 \\
\hline & Class III & 8.22 & 1.71 & 5.28 & 8.04 & 12.54 & 0.70 \\
\hline & Class IV & 6.85 & 1.35 & 5.91 & 6.39 & 13.45 & 0.32 \\
\hline & Adv. Class III & 8.11 & 1.71 & 5.37 & 7.96 & 12.98 & 0.85 \\
\hline & Adv. Class IV & 6.70 & 0.91 & 5.91 & 6.41 & 10.80 & 0.30 \\
\hline \multirow{4}{*}{ Butterfat price $(\$ / \mathrm{lb})$} & Class I & 1.58 & 0.35 & 1.16 & 1.46 & 2.50 & 0.82 \\
\hline & Class II & 1.57 & 0.36 & 1.14 & 1.47 & 2.51 & 0.72 \\
\hline & Class III & 1.56 & 0.36 & 1.14 & 1.47 & 2.50 & 0.72 \\
\hline & Class IV & 1.56 & 0.36 & 1.14 & 1.47 & 2.50 & 0.72 \\
\hline \multirow[t]{4}{*}{ Skim milk utilization (\%) } & Class I & 85.03 & 4.82 & 74.31 & 86.40 & 91.89 & -0.11 \\
\hline & Class II & 6.99 & 0.84 & 4.86 & 6.78 & 8.78 & 0.38 \\
\hline & Class III & 4.28 & 4.15 & 0.07 & 3.16 & 15.23 & 0.10 \\
\hline & Class IV & 3.60 & 1.67 & 1.20 & 3.45 & 7.54 & -0.04 \\
\hline \multirow[t]{4}{*}{ Butterfat utilization (\%) } & Class I & 50.33 & 3.54 & 43.24 & 50.79 & 57.21 & -0.08 \\
\hline & Class II & 34.22 & 3.82 & 26.82 & 34.48 & 40.41 & 0.29 \\
\hline & Class III & 4.04 & 2.61 & 0.35 & 3.35 & 11.02 & 0.00 \\
\hline & Class IV & 11.41 & 5.59 & 2.65 & 11.00 & 24.98 & -0.15 \\
\hline Uniform skim milk (\$/cwt) & & 11.46 & 1.48 & 8.76 & 11.45 & 15.21 & 0.85 \\
\hline Uniform butterfat (\$/lb) & & 1.57 & 0.35 & 1.16 & 1.44 & 2.46 & 0.79 \\
\hline Calculated uniform (\$/cwt) & & 16.57 & 2.18 & 12.51 & 16.85 & 22.87 & 1.00 \\
\hline Actual uniform (\$/cwt) & & 16.62 & 2.16 & 12.96 & 16.89 & 22.93 & 1.00 \\
\hline
\end{tabular}

mended that it be used to compare the equality of prediction MSE. Therefore, the modified Diebold-Mariano (MDM) test was also used to compare the 3 prediction methods pair-wise. By defining $z_{t}=e_{1 t}\left(e_{1 t}-e_{2 t}\right)$, where $\mathrm{e}_{1 \mathrm{t}}$ is the prediction error of the preferred method for month $t$ and $e_{2 t}$ is the prediction error of the competing method for month $t$, the MDM test can be used to pairwise test for forecast encompassing (Harvey et al., 1998; Hoffman et al., 2007). When the MDM test statistic is significantly different from 0 , the preferred method encompasses the competing method. A significant MDM statistic implies that all the information in the competing method is included in the preferred method.

The relative impact of different sources on the prediction errors was casually investigated by setting the values of 1 or more sources equal to the actual observed values in the month for which prices were predicted. Consequently, the remaining prediction error was the results of the remaining sources. For example, the sources of prediction error in the F+UTIL method were the class III and IV futures prices, utilizations of the
4 skim milk and 4 butterfat classes, and the advanced and announced butter prices. Therefore, if the actual class III prices were used, any remaining variation must be a result of the prediction errors of the other prices and utilizations.

\section{RESULTS AND DISCUSSION}

\section{Descriptive Statistics}

Descriptive statistics of monthly prices and utilizations are shown in Table 2. The mean and SD of skim milk utilization for class I were $85.0 \pm 4.8 \%$. The remainder went to products in class II $(7.0 \pm 0.8 \%)$, class III $(4.3 \pm 4.2 \%)$, and class IV $(3.6 \pm 1.7 \%)$. The mean and SD of butterfat utilization for class I was $50.3 \pm$ $3.5 \%$, with $34.2 \pm 3.8 \%$ going to class II, $4.0 \pm 2.6 \%$ to class III, and $11.4 \pm 5.6 \%$ to class IV.

The mean and SD of the announced skim milk price for class I were $\$ 12.17 \pm 1.64 /$ cwt. For classes II, III, and IV, prices were $\$ 7.40 \pm 0.91, \$ 8.22 \pm 1.71$, and 
Table 3. Prediction accuracy statistics (\$/cwt) for monthly announced class III whole milk prices based on class III futures prices ${ }^{1}$

\begin{tabular}{lccccc}
\hline Month $^{2}$ & ME & MAX & SD & MAE & RMSE \\
\hline 1 & -0.25 & 2.94 & 0.68 & 0.49 & 0.72 \\
3 & -0.72 & 7.78 & 1.85 & 1.22 & 1.97 \\
6 & -1.24 & 9.22 & 2.34 & 1.83 & 2.62 \\
12 & -1.59 & 9.15 & 2.61 & 2.32 & 3.03 \\
\hline
\end{tabular}

${ }^{1}$ Data from January 2003 to May 2007. ME = mean prediction error calculated as predicted minus actual price; $\mathrm{MAE}=$ mean absolute prediction error; $\mathrm{MAX}=$ maximum prediction error; $\mathrm{SD}=\mathrm{SD}$ of the prediction error; $\mathrm{RMSE}=$ root of the mean squared prediction error. One cwt $=45.36 \mathrm{~kg}$. One, 3-, 6-, and 12-mo-ahead predictions begin in February 2003, April 2003, July 2003 and December 2004 and continue to May 2007.

${ }^{2}$ Month into the future for which the uniform price is predicted.

$\$ 6.85 \pm 1.35 /$ cwt, respectively. Results for the advanced class III and IV skim milk prices were similar to the announced prices. Mean and SD of butterfat prices in the 4 classes were very similar at $\$ 1.57 \pm 0.36 / \mathrm{lb}(1 \mathrm{lb}$ $=0.4536 \mathrm{~kg}$ ). The class III cash price was greater than the class IV cash price in 44 of the 53 mo. Therefore, the class I skim milk price was usually being determined by the class III price. Mean and SD of the class III and class IV cash prices were $\$ 13.39 \pm 2.40 /$ cwt and $\$ 12.06 \pm 1.80 /$ cwt, respectively. When the formulas in the Appendix were used, the calculated uniform price at $3.5 \%$ butterfat was $\$ 16.57 \pm 2.18 /$ cwt. The actual uniform price in Tampa was $\$ 16.62 \pm 2.16 /$ cwt. The difference is due to changing adjustments, such as for inventory and location (USDA, 2007). For the remainder of this study, the actual uniform prices were used. Table 2 further shows that the announced class III and IV whole milk prices had correlations of 0.86 and 0.74 , respectively, with the uniform milk price.

\section{Prediction Accuracy of Class III and IV Cash Prices}

The smoothing parameter $\lambda=0.122$ was found to minimize the prediction error of the exponentially weighted moving average of the F+BASIS method. Parameter estimates for the F+UTIL method to predict utilizations of the skim milk classes were $\beta=0$ and $\gamma=$ 0 for all 4 classes (same notation as in Williams, 1987). The optimal estimates for $\alpha$ were $0.30,0.47,0.31$, and 0.03 for classes I to IV, respectively. The parameter estimates for the butterfat utilizations included $\gamma=$ 0 for all 4 classes and $\beta=0$ for classes I, II, and IV. For class III butterfat utilization, the optimal $\beta$ was equal to 1 . The optimal estimates for $\alpha$ were $0.38,0.75$, 0.00 , and 0.55 for the 4 butterfat utilization classes, respectively.

The mean and SD of the uniform price minus the class III cash price (the basis) was $\$ 3.23 \pm 1.23 / \mathrm{cwt}$ with a median of $\$ 3.34 / \mathrm{cwt}$. The correlation between the basis and the announced class III cash price was -0.44 . Thus, an increase in the class III cash price was associated with a decrease in the basis. Maynard et al.
(2005) reported a median basis of $\$ 5.18 /$ cwt with SD of $\$ 1.28 /$ cwt for Florida from January 2000 to February 2003. These authors also reported a negative correlation between basis and the class III price.

Prediction accuracy of the class III futures prices is summarized in Table 3. As expected, these results show that the short-term futures prices more accurately predicted the announced class III whole milk prices than did contracts that expired later. Short-term contracts varied more over time than did long-term contracts. The negative ME indicates that the futures prices, on average, underestimated $(P<0.01)$ the announced class III whole milk prices during the study period. Maximum prediction errors were observed in April and May 2004, which had unusually high milk prices. The RMSE increased from $\$ 0.72 /$ cwt for 1-mo-ahead contracts to $\$ 3.03$ for 12 -mo-ahead contracts. Sanders and Manfredo (2005) reported smaller RMSE of $\$ 0.82$ / cwt, $\$ 2.10 /$ cwt and $\$ 2.36 /$ cwt for 1-quarter-, 2-quarter-, and 3-quarter-ahead predictions. Using another version of the modified Diebold-Mariano test, Sanders and Manfredo (2005) found that the class III futures markets contained all information included by USDA experts and 2 time-series models for the 1-quarter- and 3 -quarter-ahead horizons, but not the 2-quarter-ahead horizon for prices from 1997 to 2003. At the 2-quarter horizon, the predictions by the USDA expert were the most accurate by all measures. Recently, another study by Sanders and Manfredo (2007) showed that 1-quarterahead price predictions provided by USDA from 1982 to 2004 were underestimated and too extreme (actual prices varied less than predicted prices). Furthermore, they found evidence that USDA prediction errors were positively correlated from one quarter to the next.

The daily settle prices of futures contracts were averaged by month in this study. The average futures price served as a proxy of the average daily settle price in the middle of the month. The largest average monthly range of daily settle prices was found for contracts that expired 2 mo from the month of trading: $\$ 1.42 /$ cwt. Contracts that expired in the same month as the month of trading had an average range of $\$ 0.33 /$ cwt, 


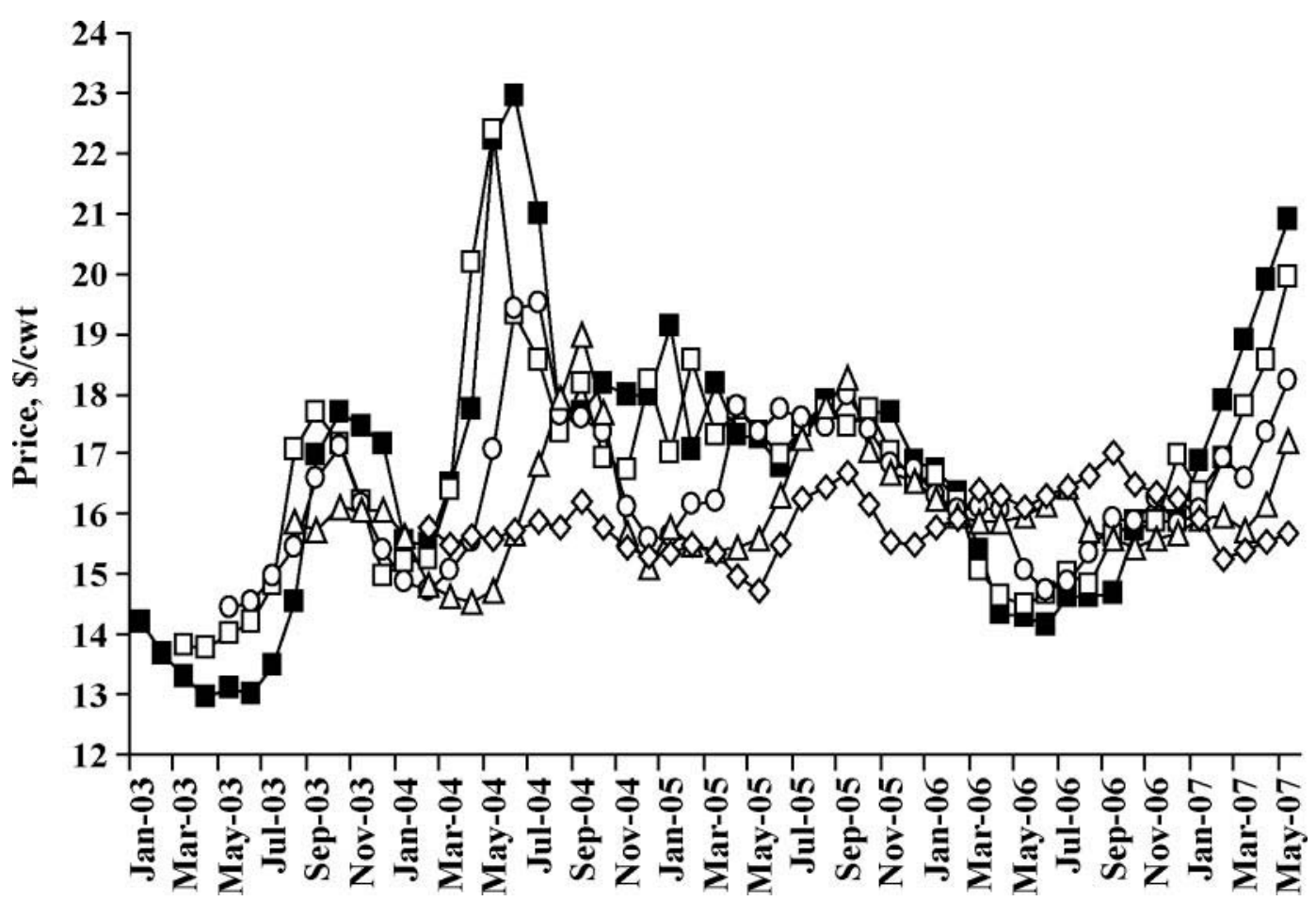

Figure 1. The F+BASIS method based on the class III futures prices and the basis: actual uniform milk prices and the 1-, 3-, 6-, and 12-moahead predictions from January 2003 to May 2007 in Federal Milk Marketing Order 6 ( $\square, 1$ mo ahead; $\bigcirc, 3$ mo ahead; $\Delta, 6$ mo ahead; $\diamond, 12$ mo ahead; $\boldsymbol{\square}$, actual uniform milk price).

with decreasing variation toward the end of the month and up to the fifth of the next month when the cash price was announced. The average range was $\$ 0.40 /$ cwt for contracts that expired 12 mo from the month of the trade. Use of the average futures price is therefore a plausible alternative to the use of the daily settle price at an arbitrarily chosen day of the month.

Short-term class IV futures contracts also predicted the announced class IV whole milk prices better than did long-term contracts. The ME for the 1-mo-ahead and 3-mo-ahead predictions were $\$ 0.06 /$ cwt and $\$ 0.14$ / cwt. Corresponding RMSE were $\$ 0.89 /$ cwt and $\$ 1.37 /$ cwt. The amount of trading was thin, however; therefore, class IV futures contracts may be poor estimators of future class IV prices.

The predicted advanced class III skim milk prices were greater than the predicted advanced class IV skim milk prices $60 \%$ of the time for 9-mo-ahead predictions and $90 \%$ of the time for 11-mo-ahead predictions of the data. Thus, the predicted advanced class I skim milk price, and therefore the predicted uniform milk price, was most often based on the class III futures prices.

\section{Prediction Accuracy of the Uniform Milk Price}

Figures 1 and 2 show the 1-, 3-, 6-, and 12-mo-ahead predictions of the uniform price from the $\mathrm{F}+\mathrm{BASIS}$ and F+UTIL methods, respectively. Short-term predictions were the most volatile and predicted the actual uniform price better than did long-term predictions. The ahead prediction from the CURRENT method was simply the uniform price in the most recently announced month (not shown).

Statistics of the 3 methods that predict the uniform milk prices are presented in Table 4. The ME from all 3 prediction methods was negative for all 12 future months, which indicates that the average actual uniform prices were greater than the predicted prices. The CURRENT method had the smallest ME for the 2-mo-ahead through the 12-mo-ahead predictions, ranging from $-\$ 0.12 /$ cwt to $-\$ 0.57 /$ cwt. The ME for the $\mathrm{F}+\mathrm{BASIS}$ and F+UTIL methods ranged from $-\$ 0.11 /$ cwt to $-\$ 1.47 /$ cwt and from $-\$ 0.30 /$ cwt to $-\$ 1.55 /$ cwt, respectively. All $12 \mathrm{ME}$ of the CURRENT method were not significantly different from 0 . All $12 \mathrm{ME}$ of the $\mathrm{F}+\mathrm{BASIS}$ and $\mathrm{F}+\mathrm{UTIL}$ methods were different $(P$ $<0.05$ ) from 0 except the 1 -mo-ahead prediction for the F+BASIS method. Therefore, the F+BASIS and F+UTIL methods were biased. This was partly caused by underprediction of the announced class III and IV whole milk prices by the futures markets. The MAE from the CURRENT method were greater than from the F+BASIS and F+UTIL methods for all 12 prediction horizons. The minimum prediction errors were close to 0 . 


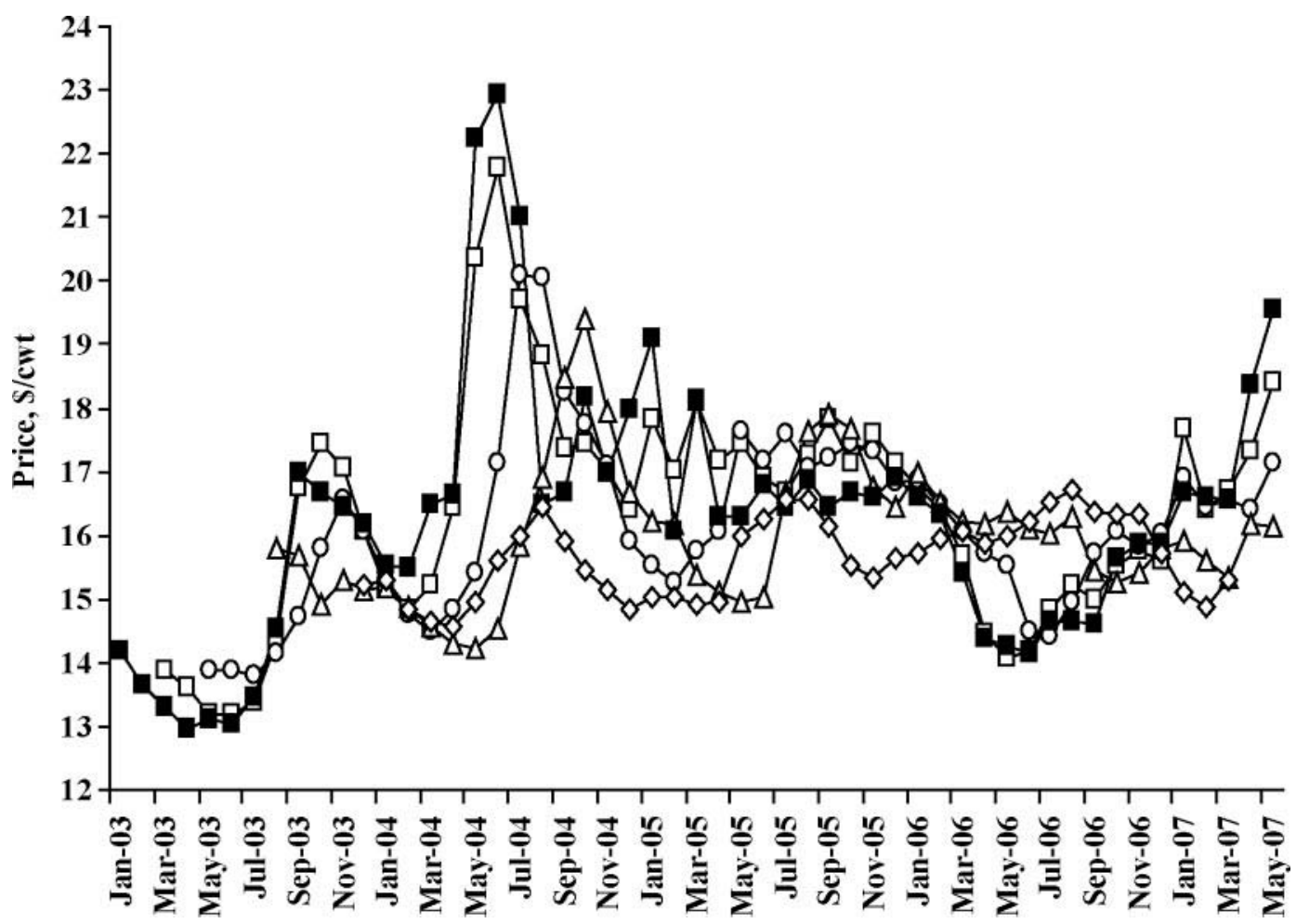

Figure 2. The F+UTIL method based on class III and IV futures prices, butterfat, and utilizations: actual uniform milk prices and the 1-, 3-, 6-, and 12-mo-ahead predictions from January 2003 to May 2007 in Federal Milk Marketing Order 6 ( $\square, 1$ mo ahead; $\bigcirc, 3$ mo ahead; $\Delta$, 6 mo ahead; $\diamond, 12$ mo ahead; $\mathbf{\square}$, actual uniform milk price).

Maximum prediction errors increased the first 4 mo but depended on the method further into the future. The maximum prediction errors were $\$ 9.91 / \mathrm{cwt}$ (12-mo-ahead) for the CURRENT method, $\$ 7.77 / \mathrm{cwt}$ (9-mo-ahead) for the F+BASIS method, and $\$ 8.58 / \mathrm{cwt}$ (7-mo-ahead) for the F+UTIL method. The prediction errors were the greatest for the spring of 2004 and the spring of 2007.

The RMSE for the CURRENT method were greater than for the other 2 methods, which appeared similar in performance. The RMSE were greater than the MAE in all cases and tended to increase rapidly the first 6 mo, after which the increase was less. Most of the MAE were between $\$ 1$ and $\$ 2 /$ cwt and most of the RMSE were between $\$ 2$ and $\$ 3 /$ cwt. Both statistics indicate that the uncertainty in the prediction of the uniform milk price was several dollars per cwt, even only a few months into the future.

Wilcoxon's signed rank test showed that the F+UTIL method was more accurate $(P<0.05)$ than the CURRENT method, except for the 1-mo-ahead predictions (Table 5). The F+BASIS method tended to have better prediction accuracy than the CURRENT method. The WSR statistics showed no significant difference in accuracy between the F+UTIL and F+BASIS methods for all 12 prediction horizons. Application of the more stringent modified Mariano-Diebold tests yielded no significant differences between the methods. Therefore, no method contained all information included in any of the other methods, and in theory, a more accurate composite method that includes the weighted predictions of both methods could be constructed (Harvey et al., 1998).

The prediction errors in this study appear to be approximately 3 times larger than the prediction errors from the Bayesian method by Petrov (1999). That study considered earlier data, different inputs, and other accuracy measures, and predicted the US milk price. It is possible that his Bayesian method would also improve the prediction accuracy of the uniform milk price in FMMO 6.

\section{Relative Importance of the Source of Prediction Errors}

The decomposition of the prediction error by source revealed that the dominant source of error was the inability of the class III futures prices to predict the announced cash prices (Table 6). When butterfat prices and all utilizations were assumed known, the remain- 
Table 4. Prediction accuracy statistics (\$/cwt) of the CURRENT, F+BASIS, and F+UTIL methods to predict the Federal Milk Marketing Order 6 uniform milk price for up to 12 mo into the future ${ }^{1}$

\begin{tabular}{|c|c|c|c|c|c|c|c|c|c|c|c|c|c|c|c|}
\hline Month $^{2}$ & \multicolumn{5}{|c|}{ CURRENT } & \multicolumn{5}{|c|}{$\mathrm{F}+\mathrm{BASIS}$} & \multicolumn{5}{|c|}{ F+UTIL } \\
\hline 2 & -0.22 & 6.44 & 2.00 & 1.25 & 1.99 & -0.35 & 3.36 & 1.16 & 0.92 & 1.20 & -0.50 & 5.36 & 1.23 & 0.87 & 1.31 \\
\hline 3 & -0.30 & 6.75 & 2.34 & 1.59 & 2.34 & -0.58 & 5.17 & 1.46 & 1.15 & 1.55 & -0.69 & 6.81 & 1.68 & 1.18 & 1.80 \\
\hline 4 & -0.38 & 7.45 & 2.54 & 1.86 & 2.54 & -0.79 & 6.57 & 1.76 & 1.39 & 1.91 & -0.87 & 7.30 & 1.97 & 1.46 & 2.13 \\
\hline 5 & -0.46 & 7.39 & 2.56 & 1.87 & 2.58 & -0.95 & 7.09 & 1.96 & 1.58 & 2.16 & -0.98 & 7.86 & 2.12 & 1.61 & 2.32 \\
\hline 8 & -0.55 & 6.85 & 2.67 & 2.20 & 2.70 & -1.28 & 7.72 & 2.26 & 1.87 & 2.57 & -1.14 & 8.54 & 2.29 & 1.82 & 2.54 \\
\hline 9 & -0.51 & 7.70 & 2.90 & 2.33 & 2.91 & -1.29 & 7.77 & 2.28 & 1.94 & 2.60 & -1.22 & 8.30 & 2.31 & 1.94 & 2.58 \\
\hline 10 & -0.52 & 8.77 & 3.09 & 2.39 & 3.10 & -1.33 & 7.76 & 2.31 & 2.02 & 2.64 & -1.30 & 8.38 & 2.33 & 1.98 & 2.64 \\
\hline 11 & -0.46 & 9.47 & 3.39 & 2.49 & 3.38 & -1.38 & 7.42 & 2.33 & 2.12 & 2.68 & -1.43 & 8.51 & 2.38 & 2.10 & 2.75 \\
\hline 12 & -0.43 & 9.91 & 3.47 & 2.48 & 3.45 & -1.47 & 7.21 & 2.33 & 2.22 & 2.73 & -1.55 & 8.36 & 2.33 & 2.15 & 2.78 \\
\hline
\end{tabular}

${ }^{1}$ Data from January 2003 to May 2007. Prediction methods: CURRENT is the last announced uniform price, F+BASIS is based on the class III futures prices and the basis, and F+UTIL is based on class III and IV futures prices, butterfat, and utilizations. ME = mean prediction error calculated as predicted minus actual price; $\mathrm{MAE}=$ mean absolute prediction error; $\mathrm{MAX}=$ maximum prediction error; $\mathrm{SD}=\mathrm{SD}$ of the prediction error; RMSE $=$ root of the mean squared prediction error. One cwt $=45.36 \mathrm{~kg}$.

${ }^{2}$ Month into the future for which the uniform price is predicted.

${ }^{3}$ All ME of the CURRENT method are not significantly different from 0.

${ }^{4}$ All ME of the F+BASIS and F+UTIL methods are different $(P<0.05)$ from 0 except the 1-mo-ahead predictions for the F+BASIS method.

ing RMSE for the F+UTIL method was approximately 1.02 times greater than when all sources were predicted. When the class III and IV prices were assumed known, but butterfat price and utilizations were predicted, the reduction in RMSE increased from $59 \%$ for the 1-moahead prediction to a reduction of approximately $85 \%$ for further ahead predictions. Between the class III and class IV futures prices, the class III was the main source of the prediction error. Predicting only the class III futures prices resulted in an RMSE reduction of $13 \%$ for the 1-mo-ahead predictions to a reduction of slightly more than $30 \%$ for further ahead predictions for the F+UTIL method. Similar results were found when the class III price was the only source of prediction error for the F+BASIS method.

\section{CONCLUSIONS}

This study assessed the accuracy of 3 prediction methods to predict the uniform milk price in Tampa,

Table 5. Wilcoxon's signed rank test and modified Mariano-Diebold test results ( $P$-values) of pair-wise comparison of the CURRENT, F+BASIS, and F+UTIL methods ${ }^{1}$

\begin{tabular}{|c|c|c|c|c|c|c|}
\hline \multirow[b]{2}{*}{ Month $^{2}$} & \multicolumn{2}{|c|}{ F+UTIL vs. CURRENT } & \multicolumn{2}{|c|}{ F+BASIS vs. CURRENT } & \multicolumn{2}{|c|}{$\mathrm{F}+\mathrm{UTIL}$ vs. F+BASIs } \\
\hline & $\mathrm{WSR}^{3}$ & $\mathrm{MDM}^{4}$ & $\mathrm{WSR}^{3}$ & $\mathrm{MDM}^{4}$ & $\mathrm{WSR}^{3}$ & $\mathrm{MDM}^{4}$ \\
\hline 1 & 0.139 & 0.358 & 0.530 & 0.001 & 0.995 & 0.085 \\
\hline 2 & 0.042 & 0.458 & 0.176 & 0.092 & 0.761 & 0.096 \\
\hline 3 & 0.022 & 0.329 & 0.110 & 0.263 & 0.794 & 0.104 \\
\hline 4 & 0.009 & 0.157 & 0.041 & 0.122 & 0.431 & 0.102 \\
\hline 5 & 0.037 & 0.104 & 0.065 & 0.084 & 0.298 & 0.126 \\
\hline 6 & 0.036 & 0.087 & 0.067 & 0.089 & 0.287 & 0.146 \\
\hline 7 & 0.010 & 0.092 & 0.040 & 0.079 & 0.489 & 0.307 \\
\hline 8 & 0.024 & 0.090 & 0.117 & 0.091 & 0.417 & 0.361 \\
\hline 9 & 0.019 & 0.146 & 0.023 & 0.142 & 0.363 & 0.372 \\
\hline 10 & 0.004 & 0.243 & 0.031 & 0.215 & 0.380 & 0.373 \\
\hline 11 & 0.011 & 0.303 & 0.086 & 0.288 & 0.580 & 0.356 \\
\hline 12 & 0.039 & 0.313 & 0.259 & 0.283 & 0.718 & 0.389 \\
\hline
\end{tabular}

${ }^{1}$ Prediction methods: CURRENT is the last announced uniform price, F+BASIS is based on the class III futures prices and the basis, and F+UTIL is based on class III and IV futures prices, butterfat, and utilizations.

${ }^{2}$ Month into the future for which the uniform price is predicted.

${ }^{3} \mathrm{WSR}=$ Wilcoxon's signed rank test (Diebold and Mariano, 1995).

${ }^{4} \mathrm{MDM}=$ modified Diebold-Mariano test (Harvey et al., 1998). 
Table 6. Percentage reduction in the total root of the mean squared error (RMSE) of the F+UTIL method when some prices or utilizations are assumed known, compared with when all prices and utilizations are predicted ${ }^{1}$

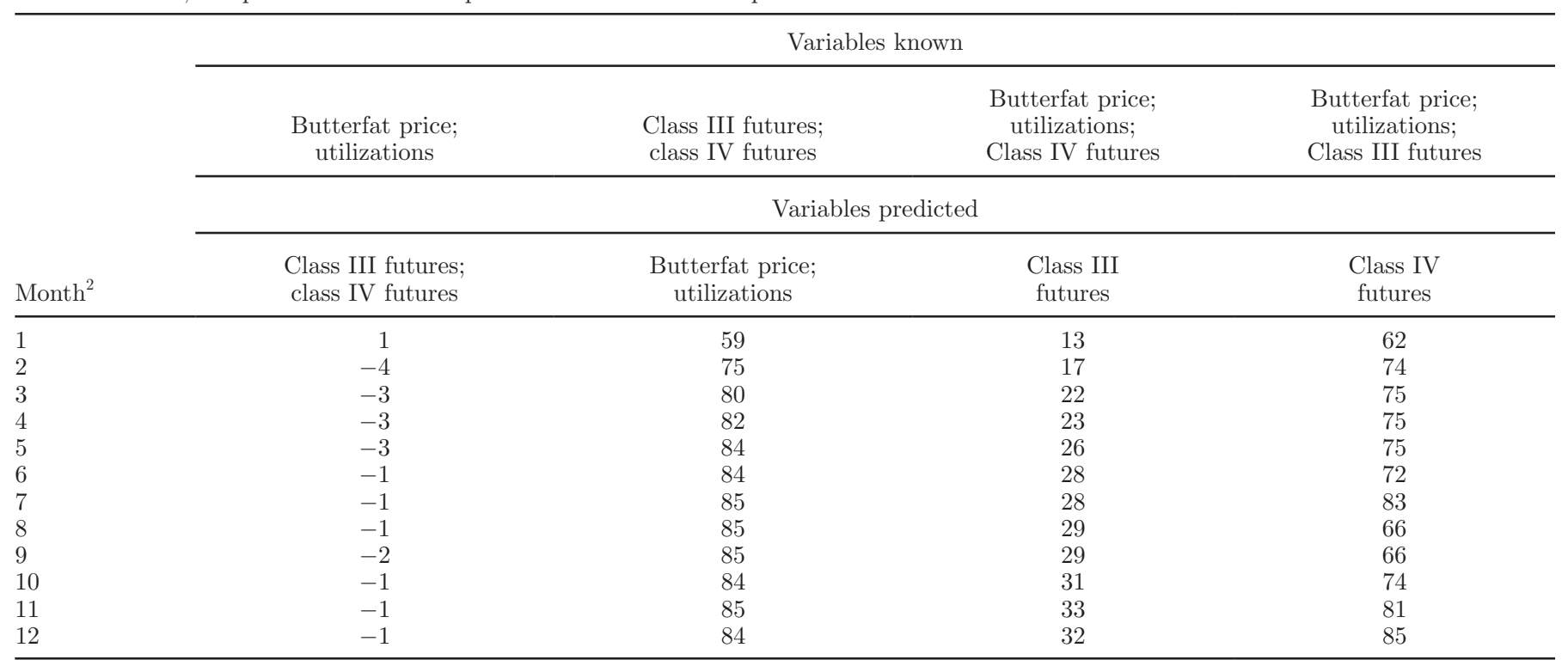

${ }^{1}$ The F+UTIL method is based on class III and IV futures prices, butterfat price, and utilizations.

${ }^{2}$ Month into the future for which the uniform price is predicted.

Florida, located in FMMO 6. Predictions were made for 1 to 12 mo into the future from January 2003 to May 2007. Actual uniform prices were typically greater than the predicted uniform prices, regardless of method. The CURRENT method was generally less accurate than the F+BASIS and F+UTIL methods, which were based on class III and IV futures prices. The F+BASIS and $\mathrm{F}+\mathrm{UTIL}$ methods did not encompass all the information available in the CURRENT method, however. The F+BASIS and F+UTIL methods were biased because they predicted lower uniform prices than were actually observed for all 12 mo into the future. The main sources for this prediction bias were announced class III cash prices that were greater than the corresponding class III futures prices. The RMSE tended to increase rapidly the first 6 mo, after which the increase was less. Most of the RMSE after 6 mo were between $\$ 2$ and $\$ 3 /$ cwt. The smallest RMSE was $\$ 0.72 /$ cwt for the 1-mo-ahead prediction from the $\mathrm{F}+\mathrm{BASIS}$ method. Thus, prediction errors of uniform milk prices using the futures markets were substantial but were more accurate than when the future uniform milk prices were assumed to be equal to the last announced uniform milk price. Prediction errors for other FMMO that use the skim milk/butterfat pricing system are expected to be similar in size. These FMMO differ only by their utilization of the 4 classes and the class I differentials. Methods that include predictions of other factors directly, such as demand for milk products, number of cows, and milk per cow, could be more accurate than the methods presented here. Fu- ture studies might compare predictions from experts, time-series methods, futures markets, and structural methods to determine the most accurate method.

\section{REFERENCES}

Bailey, K., and P. Tozer. 2001. An evaluation of federal order reform. J. Dairy Sci. 84:974-986.

CME. 2007. Chicago Mercantile Exchange Milk Class III Futures. http://www.cme.com/trading/prd/ag/milkclassIII_FCS.html Accessed Dec. 18, 2007.

Diebold, F. X., and R. S. Mariano. 1995. Comparing predictive accuracy. J. Bus. Econ. Stat. 13:253-263.

Fortenbery, T. R., R. A. Cropp, and H. O. Zapata. 1997. Analysis of expected price dynamics between fluid milk futures contracts and cash prices for fluid milk. Agric. Appl. Econ., Staff Paper Series No. 407. Univ. Wisconsin, Madison.

Harvey, D., S. Leybourne, and P. Newbold. 1997. Testing the equality of prediction mean squared errors. Int. J. Forecast. 13:281-291.

Harvey, D. I., S. J. Leybourne, and P. Newbold. 1998. Tests for forecast encompassing. J. Bus. Econ. Stat. 16:254-259.

Hoffman, L., S. Irwin, and J. Toasa. 2007. Forecast performance of futures price models for corn, soybeans, and wheat. http://www. farmdoc.uiuc.edu/irwin/research/ForecastPerformanceFutures.pdf Accessed Nov. 20, 2007.

Jesse, E., and J. Schuelke. 2002. Forecasting Class III and Class IV milk prices. Staff Paper No. 453. Dept. Agric. Appl. Econ. Univ. Wisconsin, Madison.

Makridakis, S., A. Andersen, R. Carbone, R. Fildes, M. Hibon, R. Lewandowski, J. Newton, E. Parzen, and R. Winkler. 1982. The accuracy of extrapolation (time-series) methods: The results of a forecasting competition. J. Forecast. 1:111-153.

Maynard, L. J., C. Wolf, and M. Gearhardt. 2005. Can futures and options markets hold the milk price safety net? Policy conflicts and market failures in dairy hedging. Rev. of Agric. Econ. 27:273286.

Petrov, K. M. 1999. Forecasting the dairy price complex: An application of Bayesian vector autoregression modeling. PhD Diss. The Ohio State Univ., Columbus. 
Sanders, D. R., and M. R. Manfredo. 2005. Forecast encompassing as the necessary condition to reject futures market efficiency: Fluid milk futures. Am. J. Agric. Econ. 87:610-620.

Sanders, D. R., and M. R. Manfredo. 2007. Rationality of U.S. Department of Agriculture livestock price forecasts: A unified approach. J. Agric. Appl. Econ. 39:75-85.

St-Pierre, N. R., and L. R. Jones. 2001. Forecasting herd structure and milk production for production risk management. J. Dairy Sci. 84:1805-1813.
Swantz, A. 1962. How we came to have federal milk marketing orders: What they are and what they do. J. Dairy Sci. 45:1397-1402.

USDA. 2007. Florida Fluid Milk Reports. http://fmmatlanta.com Accessed Nov. 20, 2007.

USDA-AMS. 2007. Milk Marketing Order Statistics: Class and Producer Milk and Component Prices-Description. http://www. ams.usda.gov/dyfmos/mib/fedordprc_dscrp.htm Accessed Sept. $26,2007$.

Williams, T. M. 1987. Adaptive Holt-Winters forecasting. J. Opl. Res. Soc. $38: 553-560$

\section{APPENDIX}

Price formulas for Federal Milk Market Order 6 (Florida) for May $2007^{1}$

\begin{tabular}{|c|c|}
\hline Equation & Formula \\
\hline 2 & $\begin{array}{l}\text { Uniform skim milk price }(\$ / \text { cwt })=(\text { class I skim milk price } \times \text { class I skim milk utilization })+ \\
(\text { class II skim milk price } \times \text { class II skim milk utilization })+(\text { class III skim milk price } \times \text { class III } \\
\text { skim milk utilization })+(\text { class IV skim milk price } \times \text { class IV skim milk utilization })\end{array}$ \\
\hline 3 & $\begin{array}{l}\text { Uniform butterfat price }(\$ / \mathrm{lb})=(\text { class I butterfat price } \times \text { class I butterfat utilization })+ \\
(\text { class II butterfat price } \times \text { class II butterfat utilization })+(\text { class III butterfat price } \times \text { class III } \\
\text { butterfat utilization })+(\text { class IV butterfat price } \times \text { class IV butterfat utilization }) .\end{array}$ \\
\hline 5 & Class II skim milk price $(\$ / \mathrm{cwt})=$ advanced class IV skim milk price $+\$ 0.70$. \\
\hline 6 & Class III skim milk price $(\$ /$ cwt $)=($ protein price $\times 3.1)+($ other solids price $\times 5.9)$. \\
\hline 7 & Class IV skim milk price $(\$ / \mathrm{cwt})=$ nonfat solids price $\times 9$ \\
\hline 8 & Class I butterfat price $(\$ / \mathrm{lb})=$ advanced butterfat price + (class I price differential/100). \\
\hline 9 & Class II butterfat price $(\$ / \mathrm{lb})=$ butterfat price $+\$ 0.007$. \\
\hline 10 & Class III butterfat price $(\$ / \mathrm{lb})=$ butterfat price. \\
\hline 11 & Class IV butterfat price $(\$ / \mathrm{lb})=$ butterfat price. \\
\hline
\end{tabular}

${ }^{1}$ Source: USDA-AMS (2007) and http://www.ams.usda.gov/ (accessed Dec. 17, 2007). One cwt = 45.36 kg. Some constants ("make allowances" and "yield factors") have changed since January 2003. The formulas are the same in all 4 Federal Milk Marketing Orders that use the skim milk/butterfat pricing system. The utilizations vary by order. Class I price differential varies by location and is $\$ 4.00$ in Tampa, Florida. The class I skim milk price, class II skim milk price, and class I butterfat price are calculated from the 2-wk average ("advanced") product prices for butter, NDM, cheese, and dry whey. All other prices are calculated from monthly averages. For 2007, the 2-wk product prices for butter, NDM, cheese, and dry whey are released on the last Friday no later than the 23rd of the preceding month. Final prices and utilizations are released on the last Friday no later than the fifth of the following month. The product prices are determined by weekly surveys conducted by the National Agricultural Statistics Service. 